\title{
Small Changes: \\ Using Workshops for Giving Participants a Voice
}

\author{
Joan Greenbaum \\ Computer Science Department / Aarhus University and \\ Computer Information Systems Department/LaGuardia College \\ City University of New York (on leave) \\ Kim Halskov Madsen \\ Department of Information and Media Science/Aarhus University
}

December 1991

\begin{abstract}
While technological change is often occurring at what appears to be a rapid pace, the pace at which technology is absorbed into an organization is, in fact, quite slow. This paper discusses the need for patience in accepting and preparing for organizational change. Specifically it discusses the authors' experiences in a project where many types of workshops were used to help foster an environment where the participants could find ways to express their needs for new computer support.
\end{abstract}

\section{Introduction}

Those of us in the computer field often tend to see our world as one where things happen rather fast. In the area of computer system development the eighties was a decade where an overwhelming number of new system methodologies were introduced, and where the overall perspective on system 
development shifted to include varying degrees of user involvement. Each time a change was trumpeted in a journal or at a conference there was often a chorus of researchers ready to announce the change, as if the world had in fact switched to the new idea. But in the day-to-day practice of developing computer systems, as in most practices, changes are slow, and, in fact quite small.

In this chapter we don't want to bemoan the fact that practice changes in small stages, but rather to celebrate some of the changes taking place and to point to areas where further small, inexpensive, and, rather uncomplicated changes can continue to take place. The area we focus on is that fuzzy field covering the interactions between system developers and end-users. In this paper we will try to avoid the overworked and often misused term "end-user" and instead concentrate on the people within an organization who can be encouraged and allowed to participate in making decisions about computer support in their workplace.

There has been some discussion recently (PDC'90), concerning the applicability of the Scandinavian approaches in the United States. While we can't begin to give a definitive answer to that question, this paper will tell the story of a project in which we applied some techniques from the Cooperative Design approach (Greenbaum \& Kyng, 1991) in an American setting. In particular, we used a variety of workshop techniques to help staff members in an organization better articulate their needs concerning desktop hardware and software. We feel that the story is illustrative of ways that decisions concerning computer support can be done cooperatively. As in all stories there were some successes and a few downbeat moments, but we are convinced that the road to small changes is paved with these little incidents.

The specific case discussed here concerns a project that was part of the Management Information System department's planning activities at the headquarters of a large American non-profit organization. As independent consultants we were asked to involve staff member in the ongoing MIS planning activities. The goals of the project were: 1) to enable participants to better articulate their current work activities and formulate their future expectations concerning computer support for these activities, 2) to create an ongoing learning environment where participants could learn from each other and pass their learning on to others, and 3) to provide MIS management with information for directional support concerning desktop computer software, 
specifically concerning word processing, spreadsheets and databases.

\section{Approach taken}

The project, called the Participatory Design Project or PDP, was actually initiated by senior management's request for what they called directional support concerning decisions that they wanted to make for the organization's desktop computing needs. The MIS department had prepared a first phase study of organizational computing needs that outlined the possibility of using some kind of local area network (LAN) to link desktop computers. The plan also indicated that the organization would need to switch to some form of standardized hardware and software in order to foster communication among computers and let the office staff share both information and computer resources. The initial MIS plan included interviews with department directors, and we were invited to submit a proposal that would suggest ways to find out if the original assumptions were valid. Our approach was to involve people who worked with computers on a day-to-day basis and, over a period of two and one-half months (constrained, by other management decisions within the organization) we undertook the following:

- Project establishment

- Storytelling workshop.

- Critique Workshop.

- Fantasy Workshop

- Implementation workshop

- Vendor visits

- Reporting

In our role as consultants we served as facilitators for each of the workshops and helped plan the administrative details of getting participants involved in the project, as well as working closely with them in preparing our final report and coordinating their presentation to management. Additionally, we 
gathered technical details about LAN hardware and software and information about specific desktop packages in order to better acquaint the participants with the range of technical options open to them.

Since the goals of the project were both to give management directional support and to create an ongoing learning environment for the office staff, we needed to coordinate technical and organizational information that would support the needs of both groups. As it turned out we were able to do this to the satisfaction of both sides. But this was probably due to the cooperative and helpful spirit in the workplace, and less to our prior understanding of how to handle the situation. The issue of double and sometimes conflicting objectives is not directly handled in either American or Scandinavian system development literature and probably needs more discussion among those practicing design.

\section{Project establishment}

In order to uncover the uniqueness of the individual offices it was decided to involve people from four of the five departments. In selecting the participants, department heads were asked to involve people who had the most day-today experience using existing software (Bødker, Greenbaum \& Kyng 1991). Twelve staff members were selected to participate in the project. We asked the department heads to recommend people as that was the protocol in the organization; some people ended up volunteering with the approval of their managers. The twelve participants were from a range of job titles including editors, editorial assistants, billing clerks, accountants, and secretaries. The group was fairly homogeneous in that they were quite skilled and extremely motivated.

Senior management at the organization agreed that the participants could be released from their regular activities to take part in up to six, half-day workshops. Although all of the staff were extremely busy, both management and the staff participants felt that they would get something out of the workshop process. There were some negotiations and compromise over which departments and which workers should be included. This, of course, would be expected. As a compromise we ended up involving three staff members from four of the five departments, although our original suggestion was to do 
more in depth work with one department. Later we will return to this issue since the multi-departmental workshops tuned out to be extremely fruitful.

\section{Storytelling workshop}

For the first workshop the participants were asked to prepare two short oral stories about their worst and most successful use of computers in their daily work. At the first meeting the participants shared these stories in order to initiate discussions about future software needs.

One of the stories told by a staff member, was about the day she ended up spending two hours trying to print out a letter. She went from one personal computer to another running into all sorts of problems (i.e: the lack of the right size disk drive, lack of memory and incompatible printers).

The storytelling workshop was important in two respects. First, and that was our conscious intention, the workshop provided the participants with an opportunity to become familiar with the situations in each other's offices. Second, and this turned out to be even more important, the participants also came to realize that the daily problems they faced were not unique. During the evaluation of the project participants typically stated "I didn't know that other people here have the same problems that I have".

\section{Critique Workshop}

The following three workshops were organized accordingly to a Future Workshops approach, developed by Jungk and Müllert in Germany (Jungk \& Müllert, 1987). This approach was originally used as a technique to enable citizen groups to take part in the decision process of public planning authorities such as town planning, and environmental issues. Specifically they are organized to generate ideas for future activities and to initiate actions for implementing those ideas. Future Workshops are also designed to be conducted in a way that supports people who are not typically involved in politics or other kinds of decision making. Recently the Future Workshop approach has been shown to be useful as a way of involving users in systems 
design (Kensing, Madsen 1991).

A Future Workshop is typically held in three phases: Critique, Fantasy and Implementation. In the Critique phase the purpose is to give voice to current problems and structure them so that a constructive outcome can be expected. In the Fantasy phase the purpose is to generate visions about an ideal future. In the Implementation phase the purpose is to evaluate the visions and to set up a plan of action. The approach seems to work best when each phase is facilitated by someone who is outside the process but who is familiar with the organizational issues. Additionally, it helps to arrange the workshops in a way that participants are in a comparatively "safe" situation within the organizational hierarchy so that they are not afraid to voice their problems.

A Critique workshop generally starts by having people brainstorm about critical issues. Specific brainstorming guidelines for a future workshop include:

- Speaking time is restricted to 30 seconds

- Each point of critique should be formulated as a short statement and written on a wall chart for all to see

- There is no need for rational arguments; simply stating an idea is enough

- The participants are not allowed to enter a discussion or argue against each others' points of critique.

These guidelines, while perhaps sounding rather rigid, turn out to help support participants who are sometimes afraid to speak or feel awkward phrasing their ideas. The Women's movement has often used similar guidelines, like "going around the room to hear from participants" in order to enable women to speak out (Bødker and Greenbaum, 1987).

The next step is to find three central themes from the critique and group then the critique statements according to the themes. Afterward, the participants are split into teams, each responsible for elaborating one of the themes during group discussions. At the end of the critique phase each team gives a short presentation of their elaborated critique. The presentation can be in any form found appropriate by the team, for instance a small speech, a poster, a picture, a caricature, or a play. People are encouraged to be as specific 
as possible by pointing out concrete situations where problems have arisen. At this point in time, participants are encouraged to focus only on problem issues rather than looking for solutions to the problems.

In our project, we chose to use the Critique workshop as follow-up to the storytelling session. This gave the participants a rich field of ideas to begin their critique of current problems, and helped focus their brainstorming sessions. The critique addressed a broad range of issues such as:

"information lost",

"budget and pay orders are not tracked between departments",

"do not know full capability of software",

"too much noise"

As in many American workplaces located in city office buildings, the participants were also frustrated by the lack of space, poor ventilation, and lack of privacy.

\section{Fantasy Workshop}

The structure of the fantasy workshop is similar to the structure of the critique workshop (i.e. brainstorming followed by group discussions and presentation) and it uses the same guidelines. In addition, facilitators try to encourage Participants to:

- act as if no idea is too far out - anything is possible;

- be unrestrained by existing limitations or constraints, be they economical, technological or organizational;

- remember that the vision should be something that people really desire

In the non-profit organization's fantasy workshop, as in other fantasy workshops we have facilitated, the range of ideas was wide and exhilarating. Calls for a spa and relaxation room were heard, but the staff members also talked about: 
"the need for access to all information except classified material";

"the need for an integrated communication system";

"the idea that perhaps they could find one tool that does everything";

"a boot camp" where staff members could learn or relearn specific software packages .

\section{Implementation workshop}

In general, the purpose of an implementation workshop is to initiate actions that bridge the gap between vision and reality. In setting up an implementation workshop some crucial elements for the participants and the facilitators are:

- being aware of obstacles, hindrances, and limitations

- being aware of possibilities

- bringing down to earth the visions stated in the fantasy phase

- prioritizing issues

- setting up a plan of action

In the organizational setting of our project we expanded the implementation phase to include a Storyboard technique as a way of becoming more specific about proposals for a new desktop environment. The technique is inspired from the use of storyboards in film production. As in film production, the use of storyboards in the design of computers systems is a preliminary way to sketch plans for a future desktop environment (Andriole 1989) and (Vertelny \& Curtis 1990). The technique is also related to techniques developed in the UTOPIA project in Scandinavia where they were used to help typographers get design new tools (Ehn \& Kyng 1991). Although only a little time in our project was dedicated to storyboarding, the participant's storyboards, which included posters with drawings and post-its, helped them express their ideas concretely. In the beginning of the session many of the participants were a 
little nervous about trying to express their ideas graphically, but once the work groups got together to depict their plans, the group process put the participants at ease.

The last part of the implementation workshop included setting up a plan of action. For each item the plan included what to do, when, and who should do it. Some of the actions were immediately initiated, while others were stated as suggestions that would go into the final report. One suggestion for immediate action was the simple, but effect idea that staff members could could take a guided tour around the office and see the software that was available in other departments - for example, one department used Macintosh systems, while another had a menu system available on a limited Local Area Network. One staff member in each office was responsible for getting permission from her department head and for setting up a demonstration so that participants could get an idea of the other kinds of software available within the organization itself.

\section{Vendor visits}

Vendor visits were planned in order to provide people with an opportunity to try out and compare specific desktop packages. We had looked forward to the chance to let the participants try some of their ideas out using packages that were available on the market. Yet this was the most unsuccessful part of the project, for the vendors that we contacted were not used to setting up the type of participatory sessions we had envisioned. While large vendors are used to setting up sales demonstrations for managers, it appears that they were unfamiliar or uncomfortable with the idea of providing non managerial users with an opportunity to get hands-on experience.

We did manage to offer a subgroup of participants a visit to a single hardware vendor who had invited different software vendors to take part. Although we explicitly asked the vendor to arrange a 'hands-on' session, it turned out that they arranged a conventional demonstration with no opportunity for the participants to try the packages. We made a number of attempts to arrange other visits but were unsuccessful. In fact we think that for participatory design to succeed in the United States, one of the major issues that needs to be addressed is the readiness of vendors to provide hands-on demonstrations 
to potential users. It appears that vendors tend to view managers as their potential market, steering away from 'wasting time' showing systems to non managerial users. Yet the case can easily be made that involving users in the selection process could lead to the opportunity for more sales as staff members try out new packages.

\section{Reporting}

The final report to management from the project was written by us in close cooperation with the participants. Our draft was carefully reviewed by the participants, leading to detailed a revision of the report itself.

As discussed during the implementation workshop, the participants planned how they would present their ideas to management. At a meeting between management, participants and ourselves, the participants presented the specific ideas they found most important. Management's reaction was extremely positive, finding that both the results of the project and the participatory process were useful to the organization.

\section{Concluding discussion}

From both the perspectives of management and the participants the goals of the project were achieved. According to the participants, the workshops were very helpful in enabling them to find out that other staff members had problems similar to their own and to develop strategies for coping with current problems. Additionally they became familiar with the fact that their were networks available that would suit their needs. From management's perspectives the project confirmed their original study about user needs and gave them 'directional support' for making decisions about desktop packages.

But, the project also raised a number of potential problems:

We invited the MIS director to the opening workshop, but did not include him in any of the subsequent workshop workshop activities because we wanted to avoid any "finger pointing" about the responsibility for current problems. As in many organizations, the MIS department was responsible for routine 
computer operations, and sometimes, as could be expected, there were antagonisms between other departments and MIS that grew out of pre-existing problems. While the Scandinavian approach advocates direct involvement of system developers and participants, it is important to recognize the difference between the interests of system developers as outside consultants and the internal interests of an organization. In many cases outside facilitators can be helpful to bridge the gap between current problems and future planning.

The goals of the project included both giving management directional support and enabling the staff to better formulate their expectations concerning computer support for their work activities. This situation contained a potential conflict between the needs of management and the needs of the staff. The Scandinavian projects have mainly been in a context where facilitators have supported the staff. Workers of the Scandinavian trade union projects have been able to gain influence in similar situations basically by either "by using good arguments" or "by using power (for instance threatening to deny the use of new equipment)" - the latter situation being supported by laws that allow union members to have a say about the type of technology used in the workplace (see other chapters in this volume).

Obviously the American experience is different in both legal structure and workplace practice. Clearly participatory design strategies in the U.S. have to take into account the fact that system design projects are initiated by management and need to meet the objectives of managers - both upper management and MIS management. It is probably more than a small change to begin to inject the idea that meeting worker needs could and should be included in the decision-making process. In practice this is beginning to happen. At the Participatory Design Conference (PDC'90) and at many small informal gatherings, system developers are talking about their experiences with supporting users to find ways to participate in decisions about computers in the workplace. The "good arguments" for supporting this approach have begun to gain acceptance. As in our project, many developers are showing that involving participants early in the design process and continuing participation help both managers and staff members to identify possible problem areas and to resolve misunderstandings before they develop into full-fledged design errors. Whether or not this approach can be cost-justified in traditional systems terms remains to be seen, but intuitively we know that involving users as ongoing participants in the design process doesn't have direct costs and 
may bring about concrete results in terms of both making decisions about computer support and in facilitating communication within an organization.

Based on our experience we argue for a number of issues that, we believe, need further attention both in the U.S. and in other countries where workers rights may not be explicated protected. In particular we feel that system development practices need to incorporate strategies for integrating user needs into management initiated projects. Our approach advocates using techniques, like the workshops discussed here, to enable staff members to voice their own concerns and gain experience and support in participating in the decision-making process. Clearly this can't be done in most organizations without some form of management approval and MIS involvement. Moreover the decision-making process needs the active and supportive involvement of vendors who are willing to let staff members get practical experience with new hardware and software. These last two areas represent changes in the way management views the system development process. These changes may, indeed, turn out to be anything but small.

\section{Authors note:}

We want to thank the management and staff members of the organization we worked with for their enthusiasm and encouragement during the consulting project. Their motivation and eagerness to try new approaches were particularly appreciated. The project was supported by the Computer-Human Interaction group (CHI) of the Association for Computer Machinery (ACM), and we are grateful for their financial, technical and intellectual support. The title of this article was "borrowed from" a 1973 novel by Marge Piercy which, illustrates that small changes over time have a profound impact on the way we live and work. In fact, a ventral character in the novel was a computer systems developers.

This article will appear as a chapter in the forthcoming book Participatory Design, (1992) Namioka, Aki, and Schuler, Douglas (eds), Erlbaum Associates, Hillsdale, N.J.Literature 


\section{References}

Andriole, S. (S989); Storyboard Prototypiing. Wellesley, Massachusetts: QED Infomation Sciences.

Bannon, L. (1991): From Human Factors to Human Actors, in (Greenbaum \& Kyng 1991).

Bjerknes, G., Ehn, P., Kyng, M. (1987): Computers and Democracy: A Scandinavian Challenge, Aldershot, UK: Avebury.

Bødker, S., Greenbaum, J., Kyng, M. (1991): Setting the Stage for Design as Action in (Greenbaum \& Kyng 1991).

Curtis G., Vertelney, L. (1990): Storyboards and Sketch Prototypes for Rapid Interface Visualization. Conference on Human Factors in Computing Systems. Seattle: ACM.

Ehn, P., Kyng, M. (1991): Cardboard Computers: Mocking-it-up or Hands on the Future in (Greenbaum \& Kyng 1991).

Greenbaum, J., Kyng, M. (1991): Design at Work - Coopertative Design of Computer Systems. Hillsdale, New Jersey: Lawrence Erlbaum.

Jungk, R., Müllert, N. (1987): Future Workshops: How to Create Desirable Futures. London: Institute for Social Invention.

Kensing, F., Madsen, K.H. (1991): Generating Visions: Future Workshops and Metaphorical Design in (Greenbaum \& Kyng 1991).

PDC'90 Proceedings (1990). Proceedings, Participatory Design Conference, April, 1990, Seattle. Palo Alto Ca: Computer Professionals for Social Responsibility. 